\title{
EVALUASI ASET FISIK DAN FASILITAS PADA UPT BLK PEMERINTAH KABUPATEN GARUT
}

\author{
Nurlaila Fadjarwati ${ }^{1}$, Jaka Sastrawan², Rima Midiyanti ${ }^{3}$, Septian Ahmad ${ }^{4}$ \\ Program Studi Manajemen Aset, Politeknik Negeri Bandung \\ ${ }^{2}$ e-mail: jaka.sastrawan@polban.ac.id
}

\begin{abstract}
UPT BLK is an institution formed by the Government of Garut Regency with the main task of improving the quality and quantity of the workforce. The implementation of operational activities at UPT BLK is supported by physical assets and facilities that support the implementation of training activities for participants. Physical assets and facilities that are generally in the training center include buildings, classrooms, staff rooms, practice rooms, health rooms and others. The purpose of this study was to measure the manager's perception of the performance of physical assets and facilities of the UPT BLK of the Garut Regency Government. The indicator used is a checklist of physical assets and facilities indicators which have been translated into Indonesian. This study uses a qualitative and quantitative approach with an explanatory descriptive method. Data collection techniques used are scientific observation, interviews, questionnaires and documentation studies. The results of the study indicate that the quality of physical assets and facilities in general is still relatively low. Therefore, the UPT BLK manager must pay attention to the development of physical assets and institutional facilities that are safe, clean and conducive so as to improve the training environment towards a more effective process.
\end{abstract}

Keywords: Performance Evaluation, Physical asset, Facilities

\begin{abstract}
Abstrak: UPT BLK adalah lembaga yang dibentuk Pemerintah Kabupaten Garut dengan tupoksi meningkatkan kualitas dan kuantitas tenaga kerja. Pelaksanaan kegiatan operasi pada UPT BLK didukung oleh aset fisik dan fasilitas yang menunjang pelaksanaan kegiatan pelatihan bagi peserta. Aset fisik dan fasilitas yang umumnya ada di balai pelatihan diantaranya bangunan, ruang kelas, ruang staff, ruang praktik, ruang kesehatan dan lain-lain. Tujuan penelitian ini adalah untuk mengukur persepsi pengelola mengenai kinerja asset fisik dan fasilitas UPT BLK Pemerintah Kabupaten Garut. Indikator yang digunakan adalah daftar periksa indicator asset fisik dan fasilitas yang telah diterjemahkan ke dalam Bahasa Indonesia. Penelitian ini menggunakan pendekatan kualitatif dan kuantitatif dengan metode deskriptif ekspalanatori. Teknik pengumpulan data yang digunakan yaitu observasi ilmiah, wawancara, kuesioner dan studi dokumentasi. Hasil dari penelitian menunjukkan bahwa kualitas aset fisik dan fasilitas secara umum masih tergolong rendah. Maka dari itu, pengelola UPT BLK harus memperhatikan pengembangan aset fisik dan fasilitas kelembagaan yang aman, bersih dan kondusif sehingga mampu meningkatkan lingkungan pelatihan menuju proses yang lebih efektif.
\end{abstract}

Kata Kunci: Evaluasi Kinerja, Aset Fisik, Fasilitas 
Vol 26 No 1 Tahun 2021

\section{PENDAHULUAN}

Beberapa waktu ini, topik mengenai pengelolaan aset fisik tetap menjadi diskusi yang hangat di kalangan peneliti. Pengelolaan aset fisik merupakan topik yang kompleks yang melibatkan banyak aspek dalam praktek pengelolaannya. Terlebih, pembahasan aset fisik sekarang ini selalu dikaitkan dengan aset fasilitas. Karena, keberadaan aset fisik tidak akan lepas dari keberadaan aset fasilitas. Pengelolaan aset fisik dan fasilitas menjadi rangkaian yang berkesinambungan antara satu dan lainnya. Kesadaran akan pengetahuan dalam mengelola aset fisik dan fasilitas semakin tinggi. Keberhasilan pengelola aset dalam menjaga kinerja aset fisik dan fasilitas menjadi sangat penting, karena aset fisik dan fasilitas merupakan wajah dari pelayanan suatu lembaga. Baik itu lembaga swasta atau lembaga yang berada dibawah kendali pemerintah.

Unit Pelayanan Teknis Balai Pelatihan Kerja (UPT BLK) adalah lembaga yang mempunyai tupoksi yaitu meningkatkan kualitas dan kuantitas tenaga kerja serta untuk mendorong pertumbuhan serta perkembangan produktivitas usaha kecil menengah. UPT BLK dikelola oleh Dinas Tenaga Kerja dan Transmigrasi Pemerintahan Kabupaten Garut. Pelaksanaan kegiatan operasi pada UPT BLK didukung oleh aset fisik dan fasilitas yang menunjang pelaksanaan kegiatan pelatihan bagi peserta. Aset fisik dan fasilitas yang umumnya ada di balai pelatihan diantaranya bangunan, ruang kelas, ruang staff, ruang praktik, ruang kesehatan dan lain-lain

Kegiatan pelataihan di UPT BLK akhir-akhir ini semakin meningkat. Hal itu dapat tergambar dari jumlah peserta pelatihan yang bertambah setiap tahunnya seperti yang dapat dilihat pada Tabel 1.

Tabel 1. Jumlah Peserta Pelatihan

\begin{tabular}{lc}
\hline Tahun & Jumlah Peserta \\
\hline 2015 & 130 orang \\
2016 & 400 orang \\
2017 & 432 orang \\
\hline
\end{tabular}

Adanya peningkatan jumlah peserta pelatihan harus diikuti dengan pengembangan kualitas sarana fisik dan fasilitas yang ada di UPT BLK. Pemeliharaan, pembaharuan dan inovasi merupakan faktor penentu dari kualitas aset fisik dan upaya pengembangan 
Vol 26 No 1 Tahun 2021

fasilitas lembaga yang akan menarik peserta pelatihan, staf dan/atau institusi lainnya. Penjaminan mutu aset fisik dan fasilitas ini mulai dari perencanaan, pengembangan, dan pemanfaatannya akan memastikan realisasi yang efektif dari tujuan dan sasaran yang ditetapkan di lembaga pelatihan tersebut.

Penelitian ini mencoba menggunakan indikator kualitas pembangunan aset fisik dan fasilitas untuk mengetahui pendapat tentang kualitas aset fisik dan fasilitias di UPT BLK.

\subsection{Manajemen Aset}

Menurut Hastings (2010) manajemen aset adalah serangkaian kegiatan yang berkaitan dengan mengidentifikasi aset apa saja yang dibutuhkan, mengidentifikasi kebutuhan dana, mengakuisisi aset, menyediakan sistem pendukung logistik dan pemeliharaan untuk aset, menghapus atau memperbaharui aset sehingga dapat memenuhi tujuan secara efektif dan efisien. Adapun menurut Sugiama (2013), manajemen aset adalah Ilmu dan seni yang dipadukan untuk dipakai dalam memandu pengelolaan kekayaan yang mencakup proses merencanakan kebutuhan aset, mendapatkan, menginventarisasi, melakukan legal audit, menilai, mengoperasikan, memelihara, membaharukan atau menghapuskan hingga mengalihkan aset secara efektif dan efisien. Campbell (2016) mengatakan bahwa aset dapat dikelompokan berdasarkan fisiknya menjadi real estate and facility, plant and production, mobile asset, infrastructure, dan information technology masing-masing kelompok aset tersebut mempunyai karakteristik yang berbeda satu dengan yang lainnya.

Secara umum tujuan manajemen aset adalah untuk pengambilan keputusan yang tepat agar aset yang dikelola berfungsi secara efektif dan efisien (Sugiama, 2013). Tujuan manajemen aset secara spesifik adalah agar mampu meminimisasi biaya selama umur aset bersangkutan (to minimize the whole life cost of assets), dapat menghasilkan laba maksimum (profit maximum), dan dapat mencapai penggunaan serta pemanfaatan aset secara optimum (optimizing the utilization of assets).

Campbell (2016) menyatakan bahwa dalam manajemen aset terdapat sebuah siklus yang diawali dari perencanaan (plan), evaluasi terhadap desain aset (evaluate design), memperoleh atau mengadakan aset (create procure), mengoprasikan aset (operate), melakukan pemeliharaan terhadap aset (maintain), memodifikasi aset (modify), melakukan penghapusan aset (dispose). Gambar 2 menunjukkan siklus aset dalam tahapan pengelolaan aset. 


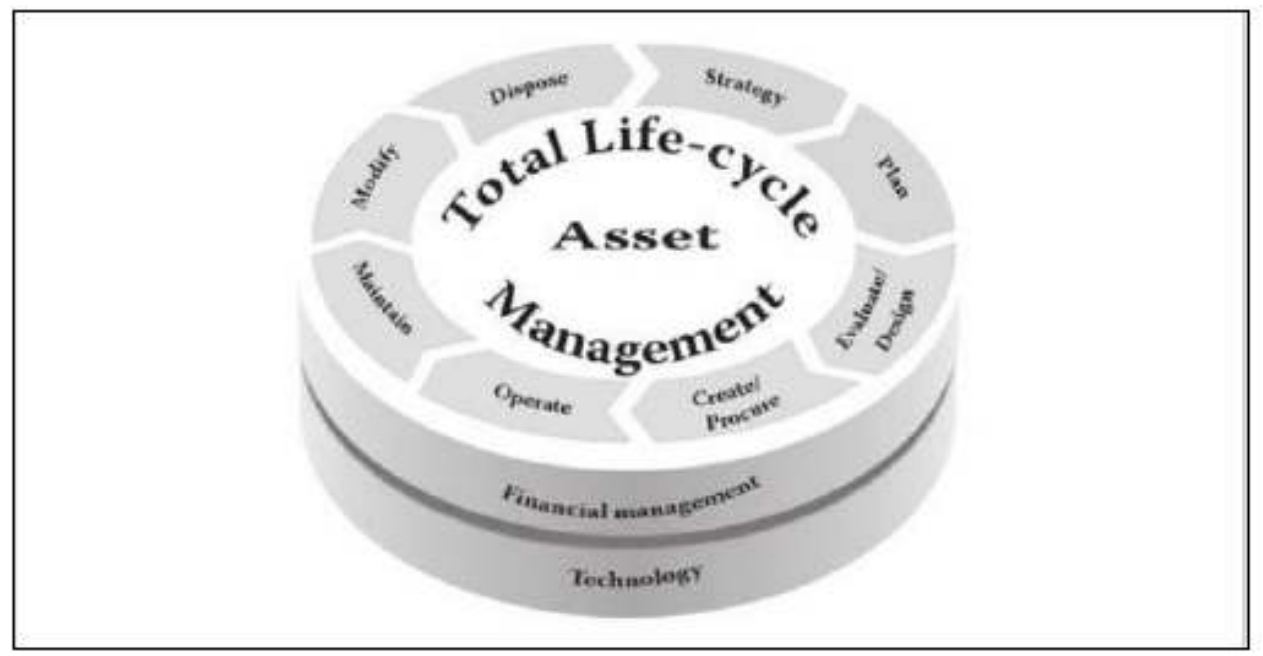

Sumber: Campbell, J.D, Andrew K.S. Jardine, and Joe McGlynn (2016).

\section{Gambar 1 Siklus Aset}

\subsection{Evaluasi Aset Fisik dan Fasilitas}

Pengukuran kinerja infrastruktur fisik akan membawa nilai tambah bagi institusi baik dalam hal pengembangan infrastruktur maupun organisasi. Tujuan pengukuran kinerja aset fisik dan fasilitas hanyalah untuk meningkatkan proses pengelolaan aset dan fasilitas demi menunjang kegiatan organisasi di masa yang akan datang. Aset fisik sangat identik dengan karakteristik aset yang dimiliki oleh bangunan dan fasilitas-fasilitas yang ada didalamnya. Kinerja dari aset fisik dan fasilitas yang optimal dapat meningkatkan penggunaan dan pemanfaatan aset tersebut demi mencapai tujuan yang telah ditentukan sebelumnya.

Torrance (2009) mengemukakan bahwa evaluasi biasanya terdiri dari beberapa aktivitas dimana didaamnnya terdapat sejumlah kegiatan seperti mengurai, membedakan, memilah sesuatu untuk digolongkan dan dikelompokkan kembali menurut kriteria yang telah ditentukan sebelumnya kemudian dicari kaitannya dan ditafsirkan maknanya sehingga dapat dipahami oleh pengelola aset. Sedangkan Morris dan Eric (2017) mengemukakan bahwa evaluasi dilakukan dengan mengumpulkan, mengevaluasi dan menggabungkan beberapa kumpulan data untuk mengidentifikasi persentase ketersediaan akhir.

Jooste dan Page (2004) mengatakan bahwa jaminan kualitas aset fisik dan fasilitas kelembagaan hanya dapat dijamin jika kondisi dan pedoman dasar diikuti. Pada dasarnya, pembangunan infrastruktur harus memberikan ruang terhadap kemampuan beradaptasi atau kemungkinan terjadinya perubahan, fleksibilitas dan aksesibilitas kepada pengguna. 
Vol 26 No 1 Tahun 2021

Menurut Sallies (dalam Uche at al, 2011) telah mengembangkan daftar periksa indikator kualitas yang menunjukkan apa yang dibutuhkan dalam evaluasi aset fisik dan fasilitas di lembaga pendidikan tinggi baik secara kualitatif maupun kuantitatif. Ini termasuk ketersediaan program pembangunan infrastruktur, kecukupan fasilitas dalam hal biaya dan relevansi dengan tujuan institusi.

\section{METODE PENELITIAN}

Pendekatan penelitian yang digunakan dalam penelitian ini adalah kualitatif dan kuantitatif (mix method). Sugiyono (2013) mengatakan bahwa mix method adalah metode penelitian yang diaplikasikan oleh peneliti untuk menjawab pertanyaan yang perlu diuji dari segi hasil (outcomes) dan prosesnya yang didapat dari hasil kombinasi antara metode kuantitatif dan kualitatif dalam satu penelitian. Pendekatan mix method digunakan dalam penelitian ini dengan tujuan menganalisis data-data kualitatif dan kuantitatif untuk mengukur persepsi dari pengelola aset mengenai kinerja aset fisik.

Sugiyono (2013) mengemukakan bahwa metode penelitian merupakan cara ilmiah untuk mendapatkan suatu data dengan tujuan dan kegunaan tertentu. Metode penelitian yang digunakan dalam penelitian ini adalah penelitian deskriptif dengan menggunakan jenis riset eksplanatori. Metode deskriptif diterapkan karena penelitian ini berupaya mengumpulkan data, menganalisis secara kritis data-data yang dikumpulkan dan menyimpulkannya berdasarkan fakta-fakta pada masa penelitian berlangsung. Adapun jenis riset eksplanatori diterapkan karena permasalahan pada objek penelitian masih samar sehingga harus diungkapkan secara jelas dan pasti menggunakan metode deskriptif eksplanatori. Dalam mendukung metode dan pendekatan dalam memperoleh data, teknik pengumpulan data yang dipilih adalah observasi ilmiah, wawancara dan studi dokumentasi.

Dalam penelitian ini, data yang akan dikumpulkan terdiri dari data primer dan data sekunder. Data primer dapat dikumpulkan melalui survei, observasi, atau eksperimen. Jenis pendekatan yang digunakan dalam penelitian ini adalah pendekatan kualitatif dengan mengumpulkan data berupa kata-kata tertulis atau lisan dari orang lain dan perilaku deskriptif yang dapat diamati.

Teknik pengumpulan data yang digunakan dalam memperoleh data primer adalah observasi ilmiah, wawancara, penyebaran kueisoner, dan studi dokumentasi. Sedangkan data sekunder diperoleh melalui buku, jurnal, atau data yang diperoleh berdasarkan publikasi pemerintah (studi normatif). Observasi langsung dilakukan dengan meninjau 
Vol 26 No 1 Tahun 2021

langsung dan mengidentifikasi kondisi aset fisik dan fasilitas di UPT BLK Kabupaten Garut. Lebih jauh, studi dokumentasi yang dilakukan dalam penelitian ini antara lain mengkaji standarisasi yang diperoleh melalui. Dalam penelitian ini dilakukan wawancara dengan pihak yang berwenang dalam mengelola aset UPT BLK dan dengan peserta pelatihan. Sedangkan, kuesioner dibagikan kepada pengelola aset fisik dan fasilititas yang bekerja di UPT BLK. Daftar periksa indikator aset fisik dan fasilitas yang digunakan merupakan adaptasi dari daftar periksa indikator aset fisik dan fasilitas yang telah diterjemahkan kedalam bahasa indonesia. Dalam penelitian ini, 25 paramater digunakan sebagai instrumen dalam meneliti kinerja aset fisik dan fasilitas yang ada di UPT BLK. Selanjutnya, dalam daftar periksa tersebut ditetapkan nilai minimal yang harus dicapai untuk menentukan nilai setuju atau tidak setuju. Setiap nilai 2,50 ke atas menandakan setuju dengan pernyataan dari instrument tersebut. Sebaliknya, poin di bawah 2,50 menandakan tidak setuju dengan pernyataan yang ada dalam instrumen. Hasil kuesioner tersebut disajikan dalam tabel sesuai urutan.

\section{HASIL DAN PEMBAHASAN}

Tabel 2 ini menunjukkan hasil rata-rata dari perspektif pengembangan aset fisik dan fasilitas. Responden menyatakan ketidaksetujuan mengenai ketersediaan gedung dan fasilitas penunjang pelatihan. Hasil rata-rata agregat yang didapat dari responden yaitu $2,44(<2,50)$.

\section{Tabel 2. Perspektif Pengembangan Aset Fisik dan Fasilitas}

\begin{tabular}{|c|c|c|c|c|}
\hline \multirow{2}{*}{ No. } & \multirow{2}{*}{ Perspektif pengembangan aset fisik dan fasilitas } & \multicolumn{3}{|c|}{ Responden } \\
\hline & & $\mathrm{N}$ & $\overline{\mathrm{x}}$ & Keterangan \\
\hline 1 & Ketersediaan gedung \& fasilitas penunjang kegiatan & 30 & 2,33 & Tidak setuju \\
\hline 2 & Tata letak bangunan dan fasilitas & 30 & 2,63 & Setuju \\
\hline 3 & $\begin{array}{l}\text { Kelengkapan bangunan \& fasilitas yang tersedia di } \\
\text { universitas untuk penggunaan penghuni }\end{array}$ & 30 & 2,33 & Tidak setuju \\
\hline 4 & Fleksibilitas gedung \& fasilitas untuk berbagai kegiatan & 30 & 2,71 & Setuju \\
\hline 5 & $\begin{array}{l}\text { Kemampuan bangunan \& fasilitas untuk memenuhi } \\
\text { jumlah pengguna sekaligus }\end{array}$ & 30 & 2,33 & Tidak setuju \\
\hline 6 & $\begin{array}{l}\text { Tingkat kenyamanan dalam bangunan (termasuk suhu, } \\
\text { penerangan, } \\
\text { bau, ventilasi, dll.) secara umum. }\end{array}$ & 30 & 2,21 & Setuju \\
\hline 7 & $\begin{array}{l}\text { Kenyamanan menggunakan fasilitas dari segi } \\
\text { kepraktisannya }\end{array}$ & 30 & 2,55 & Setuju \\
\hline 8 & Aspek keselamatan dan kesehatan di gedung \& fasilitas. & 30 & 2,41 & Tidak setuju \\
\hline & Rata-rata agregat & & 2,44 & \\
\hline
\end{tabular}


Vol 26 No 1 Tahun 2021

Lebih jauh, berdasarkan wawancara dengan pengelola UPT BLK, didapatkan informasi mengenai kekurangan ruangan untuk kelas teori dan praktek. Sehingga ruangan yang ada (eksisting) digunakan tidak hanya untuk satu fungsi dan mengakibatkan kurang optimalnya pemberian materi pelatihan. Selain itu, aspek keselamatan dan kenyamanan pun mendapatkan perhatian dari responden. Hal ini ditunjukkan dengan adanya beberapa ruangan yang memiliki kerusakan-kerusakan. Gambar 2 menunjukkan kerusakankerusakan yang terjadi di UPT BLK.

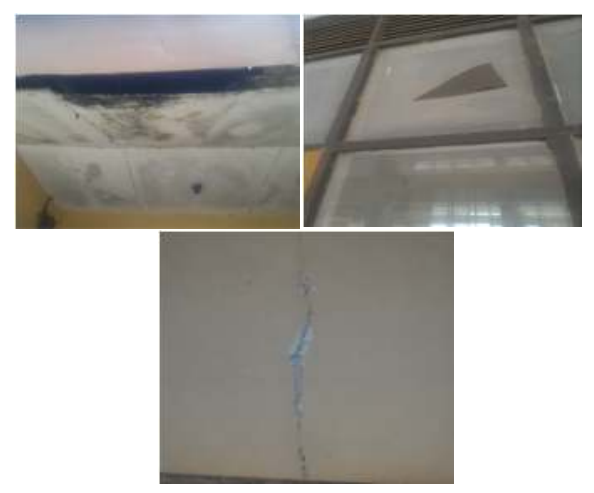

\section{Gambar 2. Bangunan rusak di UPT BLK}

Tabel 3 menunjukkan hasil rata-rata kenyamanan aset fisik dan pengembangan fasilitas yang ada di UPT BLK. Berdasarkan penilaian dari beberapa pernyataan, umumnya responden berpendapat bahwa kenyamanan aset fisik dan pengembangan fasilitas di UPT BLK masih dapat digunakan sesuai dengan peruntukkannya. Hasil dari rata-rata agregat yang didapat dari responden berada pada nilai 2,56 (>2.50). Dari empat pernyataan yang diberikan kepada responden, hanya satu pernyataan dimana responden tidak setuju. Dimana faktor keselamatan menjadi perhatian responden. Ini sesuai dengan keadaan dari UPT BLK yang memang memiliki kerusakan di beberapa bagian bangunan. Sehingga, jika tidak ada perbaikan, maka dikhawatirkan akan membahayakan keselamatan peserta pelatihan. 
Vol 26 No 1 Tahun 2021

Tabel 3 Kenyamanan Aset Fisik Dan Pengembangan Fasilitas

\begin{tabular}{|c|c|c|c|c|}
\hline \multirow{2}{*}{ No. } & \multirow{2}{*}{$\begin{array}{l}\text { Kenyamanan aset fisik dan pengembangan } \\
\text { fasilitas }\end{array}$} & \multicolumn{3}{|c|}{ Responden } \\
\hline & & $\mathrm{N}$ & $\overline{\mathrm{x}}$ & Keterangan \\
\hline 9 & Mendukung keselamatan pengguna & 30 & 2,43 & Tidak setuju \\
\hline 10 & $\begin{array}{l}\text { Kemudahan dalam mengoperasikan bagi } \\
\text { pengguna }\end{array}$ & 30 & 2,55 & Setuju \\
\hline 11 & Kemudahan dalam mengoperasikan bagi staf & 30 & 2,63 & Setuju \\
\hline 12 & $\begin{array}{l}\text { Relevan dengan materi inti pengajaran atau } \\
\text { pelatihan }\end{array}$ & 30 & 2,63 & Setuju \\
\hline & Rata-rata agregat & & 2,56 & \\
\hline
\end{tabular}

Tabel 4 menunjukkan hasil rata-rata budaya pemeliharaan dalam pengelolaan aset fisik dan fasilitas yang ada di UPT BLK. Dari lima pernyataan yang diberikan terhadap responden, tiga dari lima pernyataan resebut memiliki nilai $<2,50$. Responden menyakatakan ketidaksetujuan dari pernyataan renovasi, rehabilitasi, dan penggantian terhadap fasilitas yang rusak. Hasil dari rata-rata agregat yang didapat dari responden berada di angka 2,43 $(<2,50)$. Oleh karena itu, UPT BLK harus segera memperbaiki segala kerusakan yang ada dan mengembalikan aset dalam kondisi siap beroperasi.

Tabel 4. Budaya Pemeliharaan Dalam Pengelolaan Aset Fisik Dan Fasilitas

\begin{tabular}{lllcll}
\hline \multirow{2}{*}{ No. } & Budaya pemeliharaan dalam pengelolaan aset fisik & \multicolumn{4}{c}{ Responden } \\
\cline { 2 - 5 } & dan fasilitas & $\mathrm{N}$ & $\overline{\mathrm{x}}$ & Keterangan \\
\hline 13 & Renovasi & 30 & 2,41 & Tidak setuju \\
14 & Rehabilitasi & 30 & 2,33 & Tidak setuju \\
15 & Fasilitas dipantau secara teratur untuk & 30 & & \\
& pemeliharaan & & 2,51 & Setuju \\
16 & Penggantian terhadap fasilitas yang rusak & 30 & 2,41 & Tidak setuju \\
17 & Supervisi dan Inspeksi & 30 & 2,51 & Setuju \\
\hline & Rata-rata agregat & & 2,43 & \\
\hline
\end{tabular}

Sementara itu, Tabel 5 menunjukkan hasil rata-rata penerimaan global atas aset fisik dan pengembangan fasilitas yang ada di UPT BLK. Dari lima pernyataan yang diberikan kepada responden, responden menyakan setuju bahwa aset yang ada di UPT BLK relevan dengan tujuan pelatihan, mudah digunakan, dan sudah memiliki standarisasi global. Namun, fasilitas-fasilitas tersebut tidak sepenuhnya optimal digunakan. Berdasarkan wawancara dengan pengelola, fasilitas-fasilitas yang ada di UPT BLK seperti mesin dan alat praktek lainnya memang memilliki umur pakai yang sudah lama, sehingga 
Vol 26 No 1 Tahun 2021

terkadang ketika sedang digunakan beberapa mesin dan alat praktek tersebut mengalami kegagalan beroperasi. Pada akhirnya, peserta harus bergantian menggunakan mesin dan alat praktek tersebut. Rata-rata agregat dari kelima pernyataan yang ada di Tabel 4 menunjukkan angka 2,45, dimana angka tersebut berada dibawah angka yang ditentukan.

Tabel 5. Penerimaan Global Atas Aset Fisik Dan Pengembangan Fasilitas

\begin{tabular}{llcccc}
\hline \multirow{2}{*}{ No. } & Penerimaan global atas aset fisik dan & \multicolumn{4}{c}{ Responden } \\
\cline { 3 - 6 } & pengembangan fasilitas & $\mathrm{N}$ & $\overline{\mathrm{x}}$ & Keterangan \\
\hline 18 & Fasilitas tersedia ketika digunakan & 30 & 2,41 & Tidak setuju \\
19 & Fasilitas memadai ketika digunakan & 30 & 2,41 & Tidak setuju \\
20 & Fasilitas relevan ketika digunakan & 30 & 2,41 & Setuju \\
21 & Fasilitas mudah digunakan oleh staf & 30 & 2,63 & Setuju \\
21 & Fasilitas sudah memiliki standarisasi global & 30 & 2,41 & Setuju \\
\hline & Rata-rata agregat & & 2,45 & \\
\hline
\end{tabular}

Tabel 6 menunjukkan hasil rata-rata keamanan lingkungan pengembangan aset fisik dan fasilitas institusi pendidikan atau pelatihan yang ada di UPT BLK. Responden setuju bahwa lingkungan di sekitar UPT BLK dalam keadaan bersih, walaupun nilai dari rata-rata responden tidak signifikan dari batas angka minimal.

\section{Tabel 6. Keamanan Lingkungan Pengembangan Aset Fisik dan Fasilitas} Institusi Pendidikan atau Pelatihan

\begin{tabular}{llllll}
\hline \multirow{2}{*}{ No. } & Keamanan lingkungan pengembangan aset fisik & \multicolumn{4}{c}{ Responden } \\
\cline { 3 - 5 } & dan fasilitas institusi pendidikan atau pelatihan & $\mathrm{N}$ & $\overline{\mathrm{x}}$ & Keterangan \\
\hline 22 & Lingkungan bersih & 30 & 2,55 & Setuju \\
23 & $\begin{array}{l}\text { Pohon dan bunga ditanam untuk meningkatkan } \\
\text { kesehatan dan keamanan lingkungan }\end{array}$ & 30 & 2,63 & Setuju \\
24 & $\begin{array}{l}\text { Tidak ada bahaya yang ditemukan di lingkungan } \\
\text { pelatihan } \\
\text { Tingkat hygiene dan sanitasi lingkungan yang }\end{array}$ & 30 & 2,41 & Tidak setuju \\
& tinggi & 30 & 2,41 & Tidak setuju \\
\hline & Rata-rata agregat & & 2,50 & \\
\hline
\end{tabular}

Selain itu, responden juga setuju bahwa pepohonan dan bunga yang ditanam di sekitar lingkungan pelatihan memberikan kesan lebih indah dan nyaman. Namun, responden memperhatikan faktor hygiene dan sanitasi yang kuran baik di UPT BLK. 


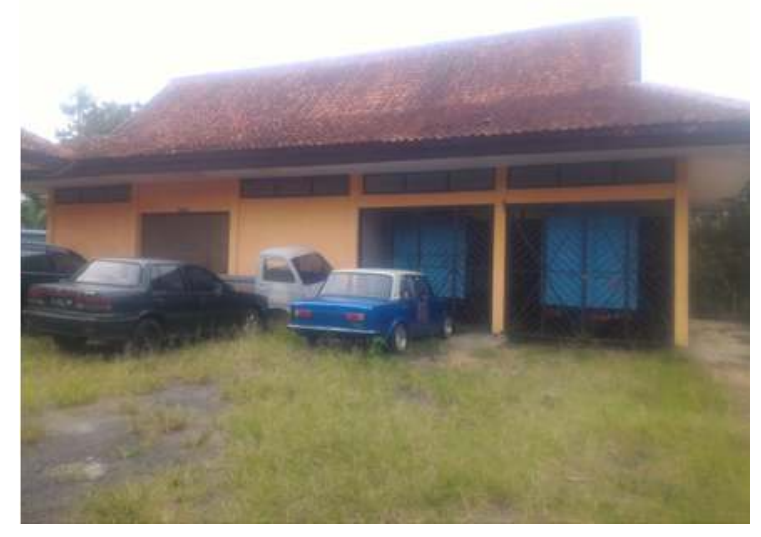

\section{Gambar 3. Ketinggian Rumput di Area Pelatihan}

Lebih jauh responden menanggapi bahwa lingkungan UPT BLK dapat memiliki potensi bahaya. Salah satunya adalah kondisi rumput yang sudah sangat tinggi di beberapa area, seperti yang ditunjukka oleh gambar 3. Kondisi tersebut memiliki potensi bahaya jika tidak segera dibenahi.

\section{KESIMPULAN DAN SARAN}

Kinerja berkaitan erat dengan kualitas, di mana istilah kualitas digunakan untuk mencerminkan tingkat keunggulan produk atau jasa yang memenuhi atau melebihi harapan orang. Jaminan kualitas dari aset fisik dan fasilitas menekankan pada pencapaian kesalahan di titik yang sangat rendah atau situasi nol kesalahan (zero mistake) dengan memastikan bahwa organisasi menetapkan dengan tepat bagaimana pengelolaan harus dilakukan dengan standar yang harus dipertahankan.

Pembangunan aset fisik dan fasilitas lembaga juga penting dalam penjaminan mutu. Jika kualitas aset fisik dan fasilitas rendah seperti yang ditunjukkan dari temuan penelitian, maka kualitas untuk mendapatkan hasil (outcomes) dari pelatihan pun akan diragukan. Hasil penelitian ini menyimpulkan bahwa pengukuran aset fisik dan pengembangan fasilitas mampu meningkatkan lingkungan pelatihan menuju proses yang lebih efektif.

Berdasarkan temuan dan implikasi penelitian, pengelola UPT BLK harus memperhatikan pengembangan aset fisik dan fasilitas kelembagaan yang aman, bersih dan kondusif sehingga dapat meningkatkan rasa memiliki, kebanggaan, keindahan dan mengembangkan budaya pemeliharaan tingkat tinggi. 
Vol 26 No 1 Tahun 2021

\section{UCAPAN TERIMAKASIH}

Penelitian ini didukung oleh Pusat Penelitian dan Pengabdian kepada Masyarakat, Politeknik Negeri Bandung Indonesia, Kontrak Nomor: 1 05.211PL1.R7/PG.00.03/2021.

\section{DAFTAR PUSTAKA}

Campbell, J. D., Jardine, A. K., \& McGlynn, J. (Eds.). (2016). Asset management excellence: optimizing equipment life-cycle decisions. CRC Press.

Hastings, Nicholas A. John. (2010). Physical Asset Management. Springer. ISBN

Jooste, J. L., \& Page, D. C. (2004). A performance management model for physical asset management. South African Journal of Industrial Engineering, 15(2), 45-66.

Morris, Scott B dan Eric M Dunleavy (2017). Adverse Impact Analysis. Routledge: New York.

Sugiama, A Gima. (2013). Manajemen Aset Pariwisata. Bandung: Guardaya Intimarta.

Sugiyono, S. (2013). Metode Penelitian Kuantitatif Kualitatif dan R\&D. Alfabeta.

Sekaran, U. (2006). Research methods for business: Business research methodology. YM Kwan (Trans.). Jakarta, Indonesia: Salemba Empat.

Torrance, Morag. (2009). The Rise of a Global Infrastructure Market throug Relational Investing. Economic Geography, Vol. 85, pp. 75-97.

Uche, C. M., Okoli, N. J., \& Ahunanya, S. (2011). Infrastructural development and quality assurance in Nigerian higher education. Journal of Emerging Trends in Educational Research and Policy Studies, 2(1), 9-16. 